\title{
Morphological Comparison of the Changes in the Gingiva of Albino Wistar Rats on Administering Tacrolimus and Sirolimus Separately: An Experimental Study
}

\author{
Karthika J' ${ }^{1}$, Rajeev Chandran $\mathrm{K}^{2}$
}

\begin{abstract}
Aim: To morphologically evaluate the effects and compare the magnitude of enlargement in the gingiva of male albino wistar rats, on the administration of tacrolimus and sirolimus.

Materials and methods: The experiment was performed on 6-week-old, male Albino Wistar rats, weighing 150-220 g. The animals were housed in pairs, in plastic bottomed cages, with husk as a bedding; in well ventilated rooms subjected to normal atmospheric conditions at $21^{\circ} \mathrm{C}$ and the same regimen of lighting ( 12 hours of light/ dark cycle) at the central animal house and fed with a standard pellet diet and water ad libitum. The rats were divided into three groups with 10 rats each and administered $1.5 \mathrm{mg} / \mathrm{kg}$ tacrolimus, $2 \mathrm{mg} / \mathrm{kg}$ sirolimus and normal saline, respectively for 12 weeks. An impression was made of the rat mandibular incisal region at the end of every third week in polysiloxane impression material, using prefabricated impression trays. The vertical height, buccolingual width and mesiodistal width of the inter-dental papilla and the keratinized gingiva were measured on the study cast using a digital caliper. Statistical analysis was then carried out, and simultaneous comparisons, between the group and within the group were made by using the analysis of variance (ANOVA) repeated measures test.

Results: The administration of both tacrolimus and sirolimus resulted in the enlargement of the gingiva, of the albino wistar rats in both the test groups $(p<0.001)$. However, rats administered tacrolimus, showed a greater percentage increase in the gingival dimensions, compared to the sirolimus administered group and the control group, in all the measured dimensions, i.e., vertical height, mesiodistal width and buccolingual width at the end of every third week, in comparison to the baseline $(p<0.001)$.

Conclusion: Both drugs, tacrolimus and sirolimus, induced gingival enlargement in the male albino wistar rats. However, the tacrolimus administered group showed a two-fold greater increase in the gingival dimensions compared to the sirolimus administered group.

Clinical significance: This study evaluates the effects of tacrolimus and sirolimus on the gingiva of albino wistar rats. Both the drugs are prime members of the immunosuppressive therapy given post-transplantation. Cyclosporine is substituted with tacrolimus to reduce the incidence and intensity of gingival enlargement in such subjects, even though both belong to the same class of drugs, namely calcineurin inhibitors. This study demonstrates that tacrolimus induces gingival enlargement whereas sirolimus does not. There is insufficient literature regarding the effects of sirolimus on gingival tissues. As per the results of this study, Sirolimus may be considered as a better substitute for cyclosporine, than tacrolimus, from a periodontal standpoint.
\end{abstract}

Keywords: Gingival enlargement, Sirolimus, Tacrolimus.

The Journal of Contemporary Dental Practice (2019): 10.5005/jp-journals-10024-2532

\section{INTRODUCTION}

$\mathrm{O}$ rgan transplants have become a norm in treating various life-threatening end-stage diseases in many medical institutions worldwide. In the past 20 years, significant advances including tissue typing and techniques such as cold ischemia and preservation solutions, now allow for approximately 6 hours of "nonfunctioning" time for hearts and other organs and 24 hours or longer for kidneys, which give a wider margin for graft survival. ${ }^{1}$ However, the development of immunosuppressive medications has needless to say be the cornerstones for the success of transplantation. ${ }^{2}$ Most transplant clinicians consider the discovery of the immunosuppressive agent cyclosporin ${ }^{3}$ to be the most significant advance in transplantation medicine. Although alternative organ procurement methods including xenografts or stem cell-derived tissue have acquired the attention as potential substitutes, transplanting organs will be a necessity for many years to come and the dire need for potent immunosuppressive drugs to tune down the immune response will hold ground too.

The likelihood of a dentist having the opportunity to treat a patient who has undergone transplantation is increasing, as many of these transplant recipients resume normal ways of life after the transplantation. ${ }^{4}$ Since tissues in allogeneic transplants
1,2Rajah Muthiah Dental College and Hospital, Annamalai University, Annamalai Nagar, Tamil Nadu, India

Corresponding Author: Rajeev Chandran K, Rajah Muthiah Dental College and Hospital, Annamalai University, Annamalai Nagar, Tamil Nadu, India, Phone: +918848856703, e-mail: dr.karthikajrajeev@gmail.com

How to cite his article: Karthika J, Chandran RK. Morphological Comparison of the Changes in the Gingiva of Albino Wistar Rats on Administering Tacrolimus and Sirolimus Separately: An Experimental Study. J Contemp Dent Pract 2019;20(4):417-423.

Source of support: Nil

Conflict of interest: None

are not genetically identical, medications used to mute the immune response are essential for graft survival. All allogeneic transplantations initially require immunosuppression, if the transplanted organs are not to be acutely rejected. ${ }^{5,6}$ Furthermore, most allogeneic solid organ transplant recipients require lifelong maintenance immunosuppression. Organ transplant recipients may present to their health care practitioner with oral complaints. Often these complaints are related to oral mucosal lesions. These lesions can be broadly related to an infectious process or a non-infectious, drug-induced process. Periodontal health in this patient population

() The Author(s). 2019 Open Access This article is distributed under the terms of the Creative Commons Attribution 4.0 International License (https://creativecommons. org/licenses/by-nc/4.0/), which permits unrestricted use, distribution, and non-commercial reproduction in any medium, provided you give appropriate credit to the original author(s) and the source, provide a link to the Creative Commons license, and indicate if changes were made. The Creative Commons Public Domain Dedication waiver (http://creativecommons.org/publicdomain/zero/1.0/) applies to the data made available in this article, unless otherwise stated. 
is often compromised. Medications used for immunosuppression and their side-effects have been related to periodontal disorders, particularly gingival overgrowth.

Cyclosporin which was the wonder drug for immunosuppression in the 19th century was implicated as the first immunosuppressant, causing gingival enlargement. Tacrolimus has been used as a substitute to cyclosporin successfully in renal and liver transplantation. However, both cyclosporin and tacrolimus belong to the class of calcineurin inhibitors (CNI). Calcineurin inhibitors have a wide range of toxicities, many of which are dose-dependent. Nephrotoxicity and Neurotoxicity are well-recognized side effects that have been documented, owing to which nearly $20 \%$ of liver transplant recipients experience chronic renal failure within 5 years.

For patients with calcineurin inhibitor-induced nephrotoxicity, conversion to sirolimus therapy has proved to be effective with ensuing improvements in renal function. Recent studies have also shown potential anti-tumor properties of sirolimus which might be of importance in patients undergoing liver transplantation for Hepatocellular carcinoma (HCC). Zimmerman et al. ${ }^{7}$ examined the role of sirolimus-based maintenance therapy in post-transplant recipients with a history of $\mathrm{HCC}$ and found that overall survival was increased in the sirolimus arm compared to the calcineurin inhibitor arm. Since its advent in immunosuppression, sirolimus has been established as a pivotal member of the $\mathrm{CNI}$-free immunosuppressive regime, which is very much in vogue today.

There are contradictory reports regarding the role of tacrolimus in causing gingival enlargement. ${ }^{8-11}$ Sirolimus has been studied extensively in the past few years, for its beneficial effects over calcineurin inhibitors. ${ }^{12}$ However, there is a lack of literature addressing the role of sirolimus in causing gingival enlargement as a separate entity, with existing literature providing inconclusive evidence. $^{13,14}$

Hence this study was undertaken to morphologically evaluate the effects of tacrolimus and sirolimus, key members of the $\mathrm{CNI}$ and CNI-free regime respectively, on the gingiva of albino wistar rats and compare the magnitude of enlargement caused by both these drugs.

\section{Materials and methods}

The experiments were performed on 6-week-old male Albino Wistar rats, weighing $150-220 \mathrm{~g}$. The animals were randomly

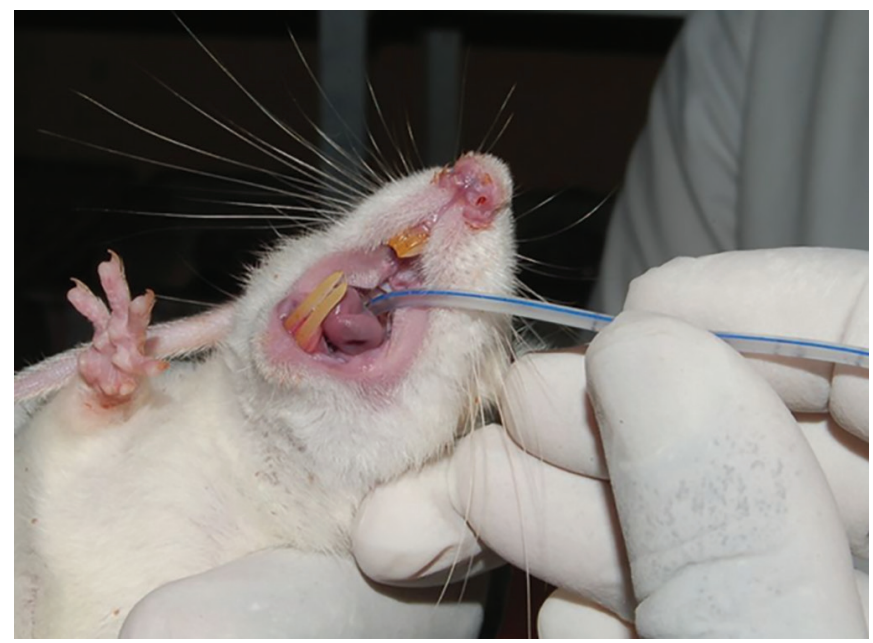

Fig. 1: Feeding of the albino wistar rats distributed into three groups of 10 rats each. The animals were housed, in similar conditions, in plastic-bottomed cages, with access to food and water ad libitum. The cages were placed in wellventilated rooms, subjected to normal atmospheric conditions and 12 hours of light and dark cycles alternatively.

\section{Ethical Approbation}

The study protocol was approved by the Institutional Animal Ethics Committee (IAEC), Rajah Muthiah Medical College, Annamalai University (Central Animal House Registration Number 160/1999/ (PSEA). The study was carried out at the Central Animal House, Rajah Muthiah Dental College, Annamalai University. The National Institute of Health guide for the care and use of Laboratory Animals (NIH Publications No. 8023, revised 1978) has been strictly followed in this study.

\section{Study Groups}

The drugs were administered to the rats, by oral feeding (Fig. 1)

- Group 1: Rats were administered tacrolimus, $1.5 \mathrm{mg} / \mathrm{kg}$ body weight, in normal saline $(0.9 \% \mathrm{w} / \mathrm{v})$ daily, for 12 weeks.

- Group 2: Rats were administered sirolimus, $2 \mathrm{mg} / \mathrm{kg}$ body weight in normal saline $(0.9 \% \mathrm{w} / \mathrm{v})$ daily, for 12 weeks.

- Group 3: Control group-rats were administered normal saline $(0.9 \% \mathrm{w} / \mathrm{v})$ alone daily, for 12 weeks.

\section{Impression Making}

An impression was made of the rat mandibular incisal region, in the polysiloxane impression material. A preliminary study model was made in die stone. Acrylic trays of approximate size were then fabricated for all the rats, with the help of this study model. The same procedure was repeated at the end of the $3,6,9$ and 12 weeks, using the pre-fabricated acrylic trays, with polysiloxane impression material, to evaluate the changes in the gingival dimensions, following the administration of the drugs (Fig. 2).

\section{Recording the Gingival Dimensions from the Cast}

The dimension of the inter-dental gingiva and the keratinized gingiva was measured on the study cast using a digital caliper (with a resolution of $0.01 \mathrm{~mm}$ ), and the following parameters were recorded, i.e., buccolingual width, mesiodistal width, and the vertical height (Fig. 3).

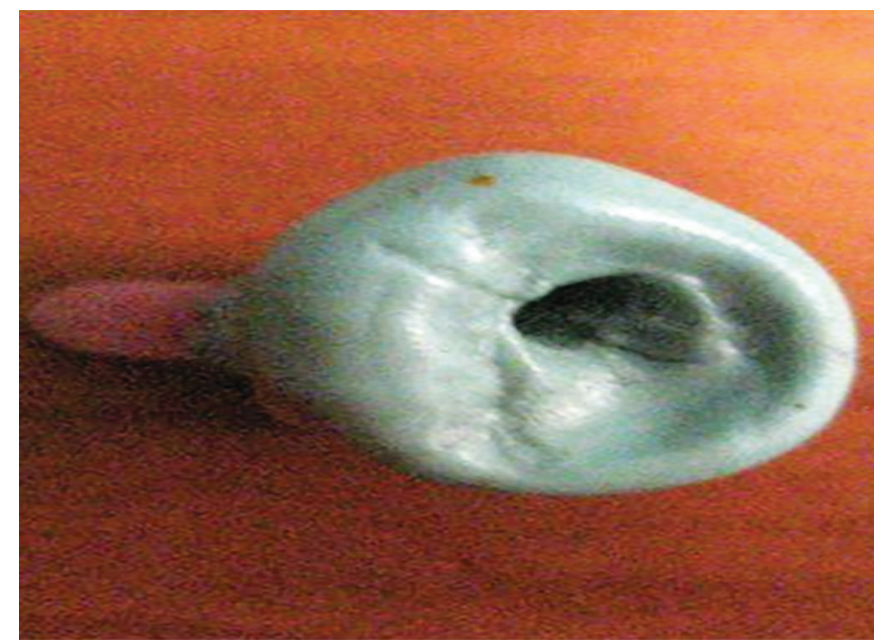

Fig. 2: Impression of the gingival area in the albino wistar rats 


\section{Statistical Analysis}

Statistical analysis was then carried out, and simultaneous comparisons were made between the groups and within the groups, by using ANOVA repeated measures test.

\section{Results}

The appearance of gingival enlargement, in as early as the third week in both the test groups could be attributed to the high dose of the drugs tacrolimus $(1.5 \mathrm{mg} / \mathrm{kg})$ and sirolimus $(2 \mathrm{mg} / \mathrm{kg})$ that were administered to both the groups and to the sensitivity of the animal model to these drugs and to the subjective measurement of the models.

The gingival enlargement in both the test groups was statistically significant as compared to the control group.

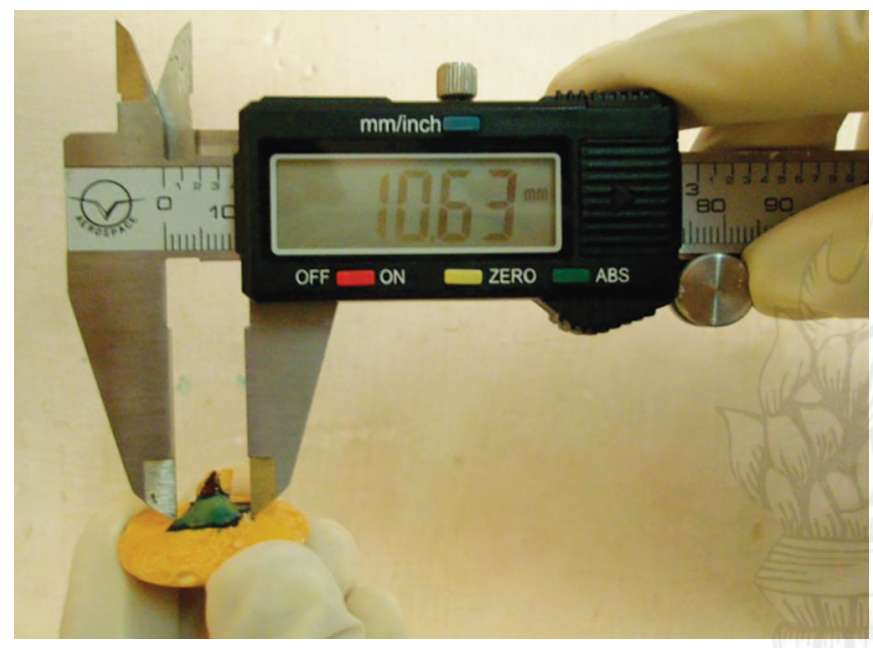

Fig. 3: Vernier caliper measurements
The tacrolimus administered group showed a greater percentage of enlargement (Fig. 4) compared to the sirolimus administered group at the end of the third, sixth, ninth and twelfth week, in all the measured dimensions, of the inter-dental papilla and the keratinized gingiva, i.e., vertical height; (Tables 1 and 2), buccolingual width; (Table 3) and mesiodistal width; (Tables 4 and 5) in the study models, when recorded with a digital caliper (resolution capacity of $0.01 \mathrm{~mm}$ )

The sirolimus administered group however showed less than one fold increase (Fig. 5) as compared to the control group, at the end of the third, sixth, ninth and twelfth week, (Fig. 6) whereas the tacrolimus administered group showed a two-fold increase compared to the control group at the same interval.

The body weight in both the test groups was similar and lesser when compared to the control group at the end of the third, sixth, ninth and twelfth week (Table 6).

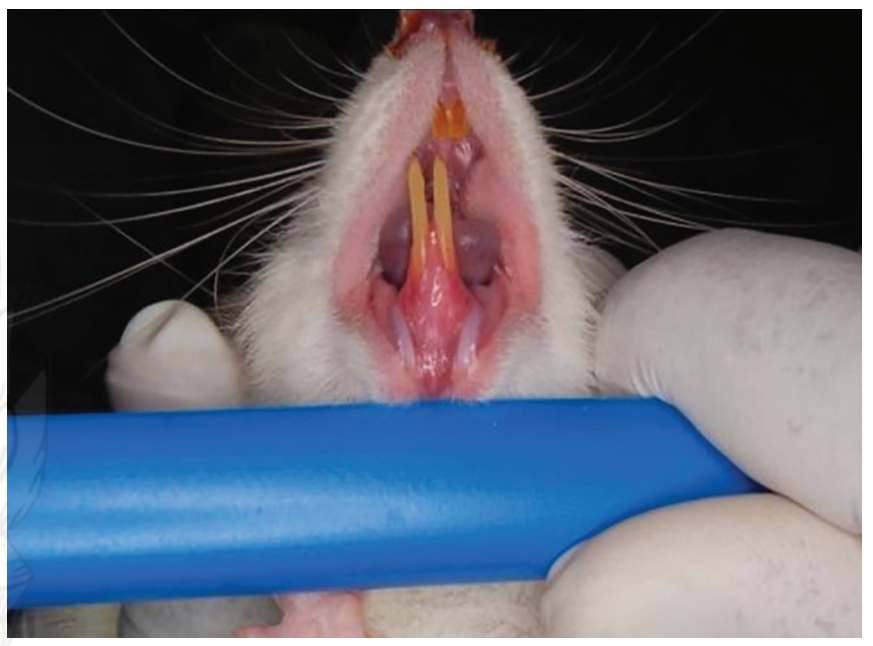

Fig. 4: Tacrolimus group at 12 weeks

Table 1: Comparison of the vertical height $(\mathrm{mm})$ of the interdental papilla between the study groups

\begin{tabular}{|c|c|c|c|c|c|c|c|c|c|c|}
\hline \multirow[b]{2}{*}{ Group } & \multicolumn{2}{|c|}{ Baseline } & \multicolumn{2}{|c|}{ 3rd week } & \multicolumn{2}{|c|}{ 6th week } & \multicolumn{2}{|c|}{ 9th week } & \multicolumn{2}{|c|}{ 12th week } \\
\hline & Mean & $S D$ & Mean & $S D$ & Mean & $S D$ & Mean & $S D$ & Mean & $S D$ \\
\hline Tacrolimus $^{1}$ & 3.23 & 0.01 & 3.53 & 0.01 & 4.08 & 0.02 & 5.12 & 0.01 & 6.65 & 0.01 \\
\hline Sirolimus $^{2}$ & 3.23 & 0.01 & 3.33 & 0.01 & 343 & 0.01 & 3.52 & 0.01 & 4.16 & 0.01 \\
\hline Control $^{3}$ & 3.23 & 0.01 & 3.29 & 0.01 & 3.37 & 0.01 & 3.42 & 0.01 & 4.06 & 0.01 \\
\hline
\end{tabular}

Table 2: Comparison of the vertical height $(\mathrm{mm})$ of the keratinized gingiva between the study groups

\begin{tabular}{lcccccccccc}
\hline & \multicolumn{2}{c}{ Baseline } & \multicolumn{2}{c}{ 3rdweek } & \multicolumn{2}{c}{ 6th week } & \multicolumn{2}{c}{ 9th week } & \multicolumn{2}{c}{ 12th week } \\
\cline { 2 - 11 } Group & Mean & SD & Mean & SD & Mean & SD & Mean & SD & Mean & SD \\
\hline Tacrolimus $^{1}$ & 6.94 & 0.01 & 7.56 & 0.01 & 8.11 & 0.01 & 9.15 & 0.01 & 10.68 & 0.01 \\
Sirolimus $^{2}$ & 6.93 & 0.01 & 7.36 & 0.01 & 7.42 & 0.01 & 7.53 & 0.01 & 7.72 & 0.01 \\
Control $^{3}$ & 6.93 & 0.01 & 7.22 & 0.01 & 7.28 & 0.01 & 7.36 & 0.01 & 7.68 & 0.01 \\
\hline
\end{tabular}

Table3: Comparison of the bucco-lingual width $(\mathrm{mm})$ of the inter-dental papilla between the study groups

\begin{tabular}{lllllllllll}
\hline & \multicolumn{2}{c}{ Baseline } & \multicolumn{2}{c}{ 3rd week } & \multicolumn{2}{c}{ 6th week } & \multicolumn{2}{c}{ 9th week } & \multicolumn{2}{c}{ 12th week } \\
\cline { 2 - 11 } Group & Mean & SD & Mean & SD & Mean & SD & Mean & SD & Mean & SD \\
\hline Tacrolimus $^{1}$ & 3.83 & 0.01 & 4.36 & 0.01 & 5.30 & 0.01 & 6.58 & 0.01 & 6.93 & 0.01 \\
Sirolimus $^{2}$ & 3.83 & 0.01 & 4.10 & 0.01 & 5.20 & 0.01 & 5.27 & 0.01 & 5.57 & 0.01 \\
Control $^{3}$ & 3.83 & 0.01 & 4.05 & 0.01 & 5.19 & 0.01 & 5.22 & 0.01 & 5.37 & 0.01 \\
\hline
\end{tabular}


Is Tacrolimus the Best Substitute for Cyclosporine-induced Gingival Overgrowth?

Table 4: Comparison of the mesiodistal width of the inter-dental papilla

\begin{tabular}{lllllllllll}
\hline & \multicolumn{2}{c}{ Baseline } & \multicolumn{2}{c}{ 3rdweek } & \multicolumn{2}{c}{ 6th week } & \multicolumn{2}{c}{ 9th week } & \multicolumn{2}{c}{ 12th week } \\
\cline { 2 - 11 } Group & Mean & SD & Mean & SD & Mean & SD & Mean & SD & Mean & SD \\
\hline Tacrolimus $^{1}$ & 2.18 & 0.01 & 2.41 & 0.01 & 3.01 & 0.01 & 3.90 & 0.01 & 4.50 & 0.01 \\
Sirolimus $^{2}$ & 2.18 & 0.01 & 2.32 & 0.01 & 2.66 & 0.01 & 2.73 & 0.01 & 2.83 & 0.01 \\
Control $^{3}$ & 2.18 & 0.01 & 2.21 & 0.03 & 2.53 & 0.01 & 2.62 & 0.01 & 2.72 & 0.01 \\
\hline
\end{tabular}

Table 5: Comparison of the mesiodistal width $(\mathrm{mm})$ of the keratinized gingiva between the groups

\begin{tabular}{lllllllllll}
\hline & \multicolumn{2}{c}{ Baseline } & \multicolumn{2}{c}{ 3rdweek } & \multicolumn{2}{c}{ 6th week } & \multicolumn{2}{c}{ 9tn week } & \multicolumn{2}{c}{ 12th week } \\
\cline { 2 - 11 } Group & Mean & SD & Mean & SD & Mean & SD & Mean & SD & Mean & SD \\
\hline Tacrolimus $^{1}$ & 6.24 & 0.01 & 7.01 & 0.01 & 8.18 & 0.01 & 9.27 & 0.01 & 9.78 & 0.01 \\
Sirolimus $^{2}$ & 6.24 & 0.01 & 6.51 & 0.01 & 7.24 & 0.01 & 7.33 & 0.01 & 7.46 & 0.01 \\
Control $^{3}$ & 6.23 & 0.01 & 6.43 & 0.01 & 7.18 & 0.01 & 7.27 & 0.01 & 7.45 & 0.01 \\
\hline
\end{tabular}

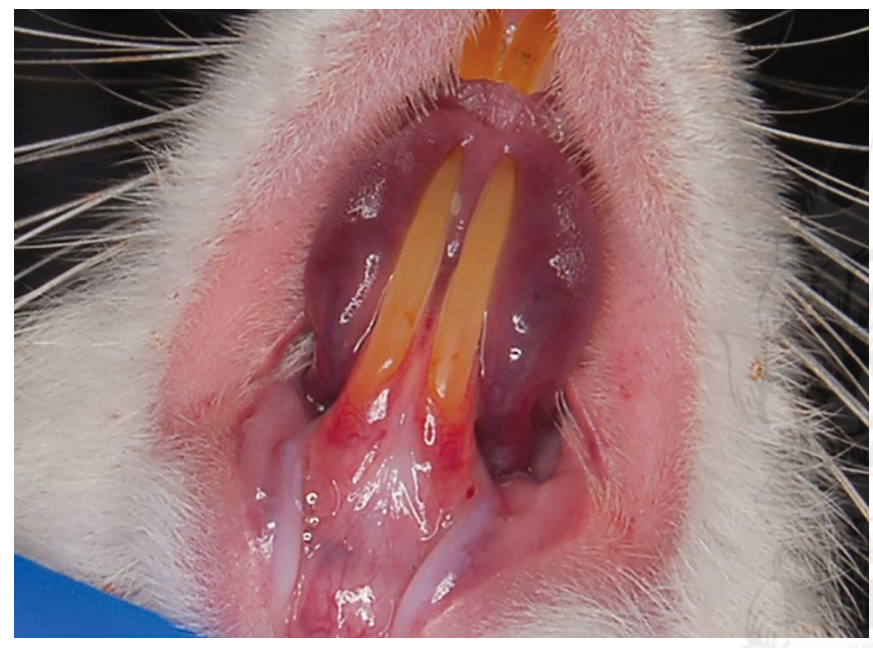

Fig. 5: Sirolimus group at 12 weeks

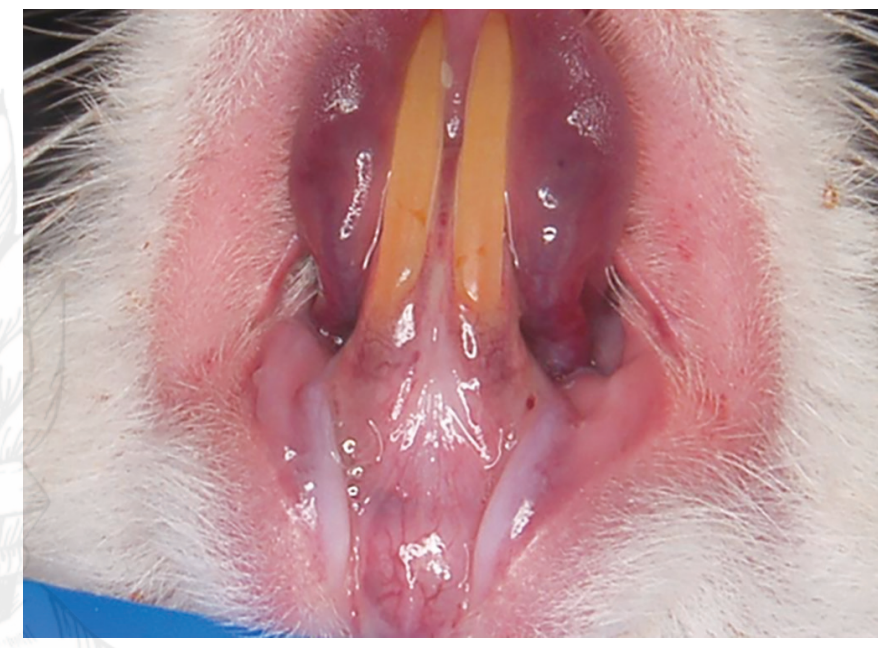

Fig. 6: Control group at 12 weeks

Table 6: Comparison of the body weight ( $\mathrm{gm}$ ) between the study groups

\begin{tabular}{|c|c|c|c|c|c|c|c|c|c|c|}
\hline \multirow[b]{2}{*}{ Group } & \multicolumn{2}{|c|}{ Baseline } & \multicolumn{2}{|c|}{ 3trd week } & \multicolumn{2}{|c|}{ 6th week } & \multicolumn{2}{|c|}{ 9th week } & \multicolumn{2}{|c|}{ 12th week } \\
\hline & Mean & $S D$ & Mean & $S D$ & Mean & $S D$ & Mean & $S D$ & Mean & $S D$ \\
\hline Tacrolimus $^{1}$ & 201 & 1.03 & 206 & 0.74 & 212 & 0.67 & 217 & 0.48 & 226 & 0.42 \\
\hline Sirolimus $^{2}$ & 200 & 0.74 & 206 & 0.74 & 212 & 0.42 & 218 & 0.67 & 226 & 0.57 \\
\hline Control $^{3}$ & 201 & 1.05 & 209 & 1.05 & 222 & 0.68 & 231 & 0.48 & 243 & 0.53 \\
\hline
\end{tabular}

The appearance of gingival enlargement in both the test groups show that the immunosuppressive action of these drugs is not devoid of this side-effect.

The role of local factors too may play a role in the enlargement and an inflammatory component should be considered.

In the present study, we observed that both tacrolimus and sirolimus induced gingival enlargement in the albino wistar rat model. However, the magnitude of gingival enlargement in the tacrolimus administered group was greater than the sirolimus administered group, in relation to the control group, during the entire duration of the study (Fig. 7).

\section{Discussion}

Transplantation immunosuppression has been primarily governed by the calcineurin inhibitors (CNI's), comprising of cyclosporin and tacrolimus. Clinical trials carried out over the past decades have established tacrolimus as a more efficacious congener and an ideal alternative to cyclosporin ${ }^{15}$ However, tacrolimus too has been associated with life-threatening side-effects, since the mode of action of both these drugs remains the same and they belong to the same class of immunosuppressants. In light of the adverse effects of calcineurin inhibitors, newer classes of immunosuppressants, with lesser side-effects and similar efficacy, have become the norm, with a calcineurin inhibitor-free therapy, catching the fancy of many a transplantation clinician today. Sirolimus, belonging to the $\mathrm{mTOR}^{16}$ class of immunosuppressants, is one such drug, which has been proven to give better survival rates post-transplantation, ${ }^{17}$ with minimal side-effects. ${ }^{18}$

Cyclosporin has been implicated, as a causative factor, in both human and animal, invitro and in vivo models, in inducing 

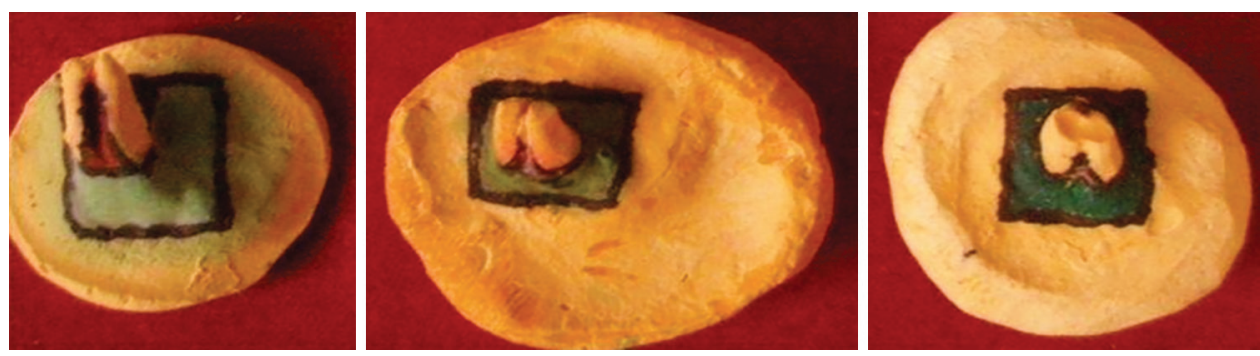

Fig. 7: Casts of tacrolimus, sirolimus and control group, respectively from left to right at 12 weeks

gingival enlargement, with its pathophysiology clearly outlined in literature. ${ }^{19}$ Tacrolimus has been used as an alternative to avoid this side-effect. However, studies evaluating, the role of tacrolimus in inducing gingival enlargement, provide contradictory results with no elaboration on the possible mechanism, by which it may induce or suppress a gingival overgrowth. ${ }^{20-28}$ Similarly to our knowledge, there are no references in the literature, of any studies, especially on the experimental animal model, examining the effects of the immunosuppressant, sirolimus on the gingival tissues, on a separate pedestal, with only two cross-sectional studies, suggesting a vague association. $^{13,29}$

Animal models ${ }^{19,26}$ such as ferrets, cats, dogs, guinea pigs, and rats have served in the past as admirable in vitro and in vivo subjects to study the effects and pathogenesis of drugs such as phenytoin, oxidipine and cyclosporin on the gingival tissues. Although the albino wistar rat model is not considered a perfect animal model for human diseases, its easy availability and handling made it the preferred choice for this animal study.

Studies in humans, evaluating the role of tacrolimus in gingival enlargement are mainly cross-sectional, which do not suggest or describe the true nature of the gingival overgrowth.

Ellis et al., ${ }^{10}$ in a prevalence study, found that patients taking tacrolimus had a significantly lower mean gingival growth compared to those who were taking cyclosporin, however, $15 \%$ of the individuals did show a significant gingival overgrowth in relation to the cyclosporin group. They implicated calcium channel blockers, in contributing to the degree of gingival enlargement.

However, in contrast to the above mentioned study, in another short term study, evaluating the incidence of tacrolimus induced gingival overgrowth in the absence of calcium channel blockers, Sekiguchi et al. ${ }^{11}$ concluded that, no significant difference in the incidence of clinically significant GO exists between the CSA and Tcr groups up to 90 days of immunosuppressive therapy.

Experimental studies carried out in the animal model, to evaluate the role of tacrolimus, in inducing gingival enlargement, too have provided contradictory results, with the following studies, demonstrating the appearance of gingival overgrowth, following commencement of drug administration.

Prabhu and Mehta, ${ }^{26}$ attributed the gingival enlargement occurring in the Sprague Dawley rats, in as early as the second week, to the high dose of tacrolimus employed in the study and the sensitivity of the animals to the drug and the objective measurement of the lesion.

Nassar et al. ${ }^{9}$ demonstrated the occurrence of gingival overgrowth in rats, after 240 days of therapy. They concluded that the deleterious side-effects of tacrolimus on the gingival tissues of rats might be time-related.

Tacrolimus belongs to the group of calcineurin inhibitors, and the interference of tacrolimus with the intracellular calciumdependent signaling pathways may partly explain the occurrence of the gingival overgrowth with this drug, but studies, in both humans and animals, that have reported a gingival enlargement have not elaborated any underlying mechanism. 9,10,11,26

Sirolimus-induced gingival enlargement too has been reported in a similar manner in literature, with inconclusive evidence. Cota et al. ${ }^{13}$ in a cross-sectional study done on Brazilian renal transplant patients, found gingival overgrowth, in a considerable number of subjects under Sirolimus based immunosuppressive regimens, although the relationship was not clinically significant.

In a recent prevalence study by Cota et al., ${ }^{29}$ gingival overgrowth in subjects under immunosuppressive regimens based on cyclosporin, tacrolimus, and sirolimus was evaluated. They found that the prevalence of GO was $60 \%$ for CsA, $28 \%$ for Tcr and $15 \%$ for Srl groups. Sirolimus and tacrolimus, although implicated in causing gingival enlargement, confounding factors like the concomitant use of calcium channel blockers and previous use of calcineurin inhibitors like cyclosporin and tacrolimus, in both the groups, tend to mar the findings.

In light of the fact, that there is a lack of literature addressing the potential role of tacrolimus and sirolimus in inducing gingival enlargement separately, in the absence of other confounding factors, this study was undertaken, to morphologically evaluate the extent of gingival overgrowth induced by tacrolimus and sirolimus (key members of the $\mathrm{CNI}$ and $\mathrm{CNI}$ free regime, respectively), individually, in male albino wistar rats.

The morphological changes, due to the administration of the drugs in the test groups were compared with the control group in terms of the vertical height, mesiodistal width and buccolingual width of the inter-dental papilla and the keratinized gingiva.

In our study, the albino wistar rats in both the test groups presented with obvious gingival enlargement, with statistically significant changes in all the measured dimensions, i.e., vertical height, mesiodistal width and buccolingual width of the gingiva compared to the control group from the third week onwards. An appearance of inflammation at the end of the third week was noted in both the test groups, which might be due to the interplay of local confounding factors and the co-incident immunosuppressive action of the drugs. However, the tacrolimus administered group was accompanied with a greater increase in the gingival dimensions compared to the sirolimus administered group and the control group, at the end of the third, sixth, ninth and 12th week. The appearance of a gingival enlargement seen as early as three weeks, after the commencement of the study, could be attributed to the high dose of the drugs administered, the sensitivity of the animal to the drugs and also to the subjective measurements carried out, as mentioned by Fu et al. and Prabhu and Mehta. ${ }^{26}$

The occurrence of gingival enlargement, upon gastric administration of this calcineurin inhibitor in rats, in our study suggests that tacrolimus has the potential to cause gingival enlargement and is not devoid of this side-effect. 
Sirolimus belongs to a different class of immunosuppressants, i.e., mTOR inhibitors and has a different mode of functioning; however, this drug too demonstrated a certain amount of gingival enlargement. When matched with the control group, the sirolimus administered group showed less than one fold increase in the gingival dimensions at the end of every third week, up to the twelfth week, while the tacrolimus administered group showed a two-fold increase in comparison to the sirolimus administered group and the control group. The role of sirolimus in causing gingival enlargement has not been studied till now, further studies are needed to explain the possible pathophysiologic mechanisms leading to such growth, however small.

Local factors too may be a confounding factor, in this study, in causing the gingival enlargement. An inflammatory component in the gingival enlargement induced in the test groups cannot be ruled out.

Because this is an animal study, extrapolation of this data has its limitations. Further studies are needed to explain the true nature of sirolimus induced gingival enlargement since this drug has not been studied in that context until now. Also, the contradictory findings in relation to tacrolimus induced gingival enlargement too need to be substantiated with studies describing the mechanism of this drug in causing gingival enlargement.

Cosmetic disfigurement resulting due to the enlargement of gingiva has a reasonable psychological impact on patients visiting dental offices today. In light of the overwhelming fact and estimation that the need for organ transplants has been steadily increasing and is only slated to increase in the coming years, the probability of such a patient approaching the dental office is more, since these patients resume normal ways of life after surgery. It is of prime importance that the periodontist be aware of the medications, that form the posttransplant regime of such patients and the side-effects associated with them, especially those affecting the oral tissues. From an esthetic point of view, within the limits of this study, it can be concluded that sirolimus causes a much lesser degree of gingival enlargement compared to tacrolimus, although not completely devoid of this side-effect. Sirolimus may be suggested as a better alternative as compared to tacrolimus, to overcome or avoid the incidence of disfiguring gingival enlargement in transplant patients, within the realms of their immunosuppressive regime. However, further animal and human studies, with elaborate histological and histometric analysis are mandatory, to establish this fact and understand the true nature of the gingival enlargement, observed in this study, caused by both these drugs.

Within the limits of this study, it can be concluded that, although tacrolimus and sirolimus both induce gingival enlargement, tacrolimus causes a greater degree of gingival enlargement compared to sirolimus, in the experimental animal model.

Since these results have been established in an experimental animal model, they can only serve as indirect evidence, due to the differences between animals and humans. Further animal and human studies with elaborate histological and histometric evaluation are required to understand the true nature of the gingival enlargement, induced by these drugs

\section{References}

1. Andrews PA. Recent developments in Renal transplantation. BMJ 2002;324:530-534.

2. Pillai AA, Levitsky J. Immuno update. World J Gastroenterol 2009; 15(34):4225-4233.
3. Martin L, Michele S, Kellermann G, et al. Cyclosporin A induced gingival overgrowth is not associated with myofibroblast transdifferentiation. Braz Oral Res 2010;24(2):182-188.

4. Sollecito TP. Transplantation medicine. Burkitts Oral Medicine Chapter 19:503-520.

5. O'Donnell M, Parmenter KL . Transplant medications. Crit Care Nurs Clin North Am 1996; 8: 253-271.

6. Braun F, LorfT, Ringe B. Update of current immunosuppressive drugs used in clinical organ transplantation. Transpl Int 1998;11:77-81.

7. Zimmerman MA, Trotter JF, Wachs M, et al. Sirolimus-based immunosuppression following liver transplantation for hepatocellular carcinoma. Liver Transpl 2008;14:633-638.

8. Kaig, Kelly D, Shaw L. Investigation of the effect of FK506 (tacrolimus) and cyclosporin on gingival overgrowth following paediatric liver transplantation. Int J Paediatr Dent 2002; 12:398-403.

9. Nassar CA, Nassar PO, Andia DC, et al. The effects of up to 240 days of tacrolimus therapy on the gingival tissues of rats, a morphological evaluation. Oral Dis 2008;14:67-72.

10. Ellis JS, Seymour RA, Taylor JJ, et al. Prevalence of gingival overgrowth in transplant patients immunosuppressed with tacrolimus. J Clin Periodontol 2004;31:126-131.

11. Sekiguchi RT, Paixa CG, Saraiva L, et al. Incidence of tacrolimusinduced gingival overgrowth in the absence of calcium channel blockers, a short-term study. J Clin Periodontol 2007;34:545-550.

12. Thervet $\mathrm{E}$. Sirolimus therapy following early cyclosporin withdrawal in transplant patients: Mechanism of action and clinical results. Int J of Nanomed 2006;1(3):269-281.

13. Cota LO, Oliveira AP, Costa JE, et al. Gingival status of Brazilian renal transplant recipients under sirolimus-based regimens. J Periodontol 2008;79(11):2060-2068.

14. Johnsson C, Gerdin B, Tufveson G. Effects of commonly used immunosuppressants on graft-derived fibroblasts. Clin Exp Immunol 2004;136:405-412.

15. Pierre E. Wallema CQ, Reding R. FK506 (Tacrolimus), A Novel Immunosuppressant in Organ Transplantation, Clinical, Biomedical and Analytical Aspects. Clin Chem 1993;39(11):2219-2228.

16. Fairbanks KD, Eustace JA, Fine $D$, et al. Renal Function Improves in Liver Transplant Recipients When Switched From a Calcineurin Inhibitor to Sirolimus. Liver Transpl 2003;9:1079-1085.

17. Bumbea $V$, Kamar $N$, Ribes $D$, et al. Long-term results in renal transplant patients with allograft dysfunction after switching from calcineurin inhibitors to sirolimus. Nephrol Dial Transplant 2005;20: 2517-2523.

18. De Beek DV, Kremers WK, Kushwaha SS, et al. No Major Neurologic Complications With Sirolimus Use in Heart Transplant Recipients. Mayo Clin Proc 2009;84(4): 330-332.

19. Hassell TM, Hefti AF. Drug-Induced Gingival Overgrowth: Old Problem, New Problem, CROBM 1991;2(1):103-137.

20. Bader G, Lejeune S, Messner M. Reduction of cyclosporin induced gingival overgrowth following a change to tacrolimus - A case history involving a liver transplant patient.J Periodontology 1998;69(6):729-732.

21. Hernandez G, Arriba L, Lucas M, et al. Reduction of severe gingival overgrowth in a kidney transplant patient by replacing cyclosporin A with tacrolimus. J Periodontol 2000;71(10):1630-1636.

22. James JA, Boomer $S$, Maxwell AP, et al. Reduction in gingival overgrowth associated with conversion from cyclosporin $A$ to tacrolimus. J Clin Periodontol 2000;27(2):144-148.

23. James JA, Jamal S, Hull PS, et al. Tacrolimus is not associated with gingival overgrowth in renal transplant patients. J Clin Periodontol 2001;28(9):848-852.

24. Chabria D, Weintraub RG, Kilpatrick NM. Mechanisms and management of gingival ov ergrowth in paediatric transplant recipient- a review. Int J Paediatric Dentistry 2003;13(4):220-229.

25. Gagliano N, Moscheni C, Dellavia C, et al. Immunosuppression and gingival overgrowth: gene and protein expression profiles of collagen turnover in FK506-treated human gingival fibroblasts. J Clin Periodontol Feb; 32(2): 167-173. 
26. Prabhu A, Mehta DS. A Morphological Comparison of Gingival Changes Influenced by Cyclosporin and Tacrolimus in Rats: An Experimental Study. J Periodontol 2006;77:265-270.

27. Oliveira CF, Ferreira SD, Lages EJ, et al. Demographic, pharmacologic, and periodontal variables for gingival overgrowth in subjects medicated with cyclosporin in the absence of calcium channel blockers. J Periodontol 2007;78(2):254-261.
28. Cezario ES, Cota LO, Ferreira SD, et al. Gingival overgrowth in renal transplant subjects medicated with tacrolimus in the absence of calcium channel blockers. Transplantation 2008;85(2): 232-236.

29. Cota LOM, Aquino DR, Francoc GCN, et al. Gingival overgrowth in subjects under immunosuppressive regimens based on cyclosporin, tacrolimus, or sirolimus. J Clin Periodontol 2010;37(10):894-902. 